\title{
INCREASED UPTAKE OF ZINC IN MALIGNANT CELLS IS ASSOCIATED WITH ENHANCED ACTIVATION OF MAPK SIGNALING AND P53-DEPENDENT CELL INJURY
}

\begin{abstract}
Emil Rudolf
Charles University in Prague, Faculty of Medicine in Hradec Králové, Czech Republic: Department of Medical Biology and Genetics

Summary: Excess intracellular zinc has been demonstrated to be responsible for cell injury and cell death in various experimental as well as clinical models. While the cells possess a system of mechanisms regulating intracellular zinc homeostasis, their saturation by acutely increased zinc levels or by a sustained exposure to elevated zinc levels results in liberation of free zinc stores within the cells and ultimate cell damage and cell death. Here we report that in Hep-2 malignant cells enhanced uptake of zinc causes activation of mitogen-activated protein kinase (MAPK) signaling with resulting p53-dependent cell injury which can be significantly prevented by specific p53 inhibition and by prevention of oxidative stress. Our observations are consistent with the view that subacutely increased intracellular free zinc levels stimulate via oxidative stress p53-dependent pathways which are responsible for the final cell damage in tumor cells.
\end{abstract}

Key words: Hep-2 cells; Zinc; MAPK; p53; Cell injury; Cell death

\section{Introduction}

Zinc is one of the most abundant inorganic elements in mammalian cells, where it regulates a wide variety of biological activities including maintenance of structural as well as functional integrity of cells (2). Despite the fact that inside cells zinc is mostly found in a bound form, its intracellular homeostasis has to be strictly regulated, as it has been amply demonstrated that increased intracellular zinc abundance contributes to cellular injury and, in some cases, leads to ultimate cell death (5).

The type of zinc-inflicted injury and its final outcome depends on several factors, such as the extent and timing of zinc influx and efflux as well as the availability of intracellular zinc trafficking and sequestering mechanisms. Zinc transport and trafficking is generally regulated by two gene families - the ZnT proteins and the Zip family. ZnT and Zip proteins seem to have opposite roles in cellular zinc homeostasis, with $\mathrm{ZnT}$ transporters reducing intracellular cytoplasmic zinc levels by promoting zinc efflux from cells, while Zip transporters increase intracellular cytoplasmic zinc by promoting extracellular zinc translocation into cytoplasm (9).

Recent efforts have led to the identification of at least 9 members of the ZnT family and 5 members of the Zip family of transporters, with each of them showing distinct expres- sion and localization in individual tissues and cells. Moreover, upon zinc starvation or excess exposure, particular zinc transporters also show varying response rates in terms of their downregulation, upregulation and localization (9).

When the cell is exposed to conditions which acutely or subacutely increase its intracellular zinc concentrations, thus bypassing normal zinc homeostatic mechanisms, cellular status becomes compromised and several stress response cascades are activated. Among them, mitogen-activated protein kinase (MAPK) cascades appear to play a prominent role. They include three major kinases: extracellular signal-regulated kinase (ERK), c-JUN N-terminal kinase (JNK) and p38 kinase, which under physiological conditions (transient activation) mediate cell growth, proliferation and generally cell survival (13). When activated persistently, however, they may mediate growth arrest and finally promote cell death.

In our previous report we showed that externally supplied zinc induces cell injury and apoptosis in Hep-2 cells during $96 \mathrm{~h}$ of treatment, in particular by means of oxidative stress, activation of p53 pathway as well as via direct zinc effect on mitochondria (15). Presently, we wanted to investigate the effect of subacute zinc exposure on Hep-2 cells viability while focusing on putative involvement of MAPK cascades and their functional linkage with p53-dependent signaling. 


\section{Materials and methods}

\section{Chemicals}

Zinc sulfate, 6-diamidino-2-phenylindole (DAPI), Triton-X, horseradish peroxidase, dithiotreitol (DTT), Chelex100, p38-specific inhibitor SB 203580, JNK-specific inhibitor SP600125 and ERK (MEK)-specific inhibitor U0126 were purchased from Sigma-Aldrich (Prague, Czech Republic). p53-specific inhibitor Pifithrin- $\alpha$ (2-(2-imino4,5,6,7-tetrahydrobenzothiazol-3-yl)-1-p-tolylethanone, $\mathrm{HBr}$ ) and sodium catalase mimetic MnTMPyP were acquired from Calbiochem (EMD Biosciences, Inc., La Jolla, USA). Primary antibodies (p-53 and phospho-p53) were obtained from Sigma-Aldrich (Prague, Czech Republic) and polyclonal rabbit anti-human caspase-3 was purchased from Dako (Glostrup, Denmark). Secondary antibodies were from Alexis Corporation (Lausen, Switzerland). Newport Green diacetate was obtained from Molecular Probes (Eugene, USA). All other chemicals were of highest analytical grade.

\section{Cell line and treatment conditions}

The continuous cell line Hep-2 (ECACC, No. 86030501, Porton Down) was maintained in a humidified $5 \% \mathrm{CO}_{2}$ atmosphere at $37^{\circ} \mathrm{C}$ in Dulbecco's modified Eagle's medium - DMEM (Gibco, Prague, Czech Republic) supplemented with $10 \%$ bovine serum (BS) (Gibco, Prague, Czech Republic), penicillin $\mathrm{G}(100 \mathrm{U} / \mathrm{ml})$ and streptomycin (100 $\mu \mathrm{g} / \mathrm{ml})$.

Cells were plated into standard cultivation media and left overnight in an incubator at the above specified conditions. Thereafter, they were exposed for $24 \mathrm{~h}$ to zinc-deficient medium which was generated by incubation of BS with $10 \%$ Chelex-100 overnight at $4{ }^{\circ} \mathrm{C}$ and by its addition to DMEM. Thus treated cells were exposed to $150 \mu \mathrm{M}$ zinc for $24 \mathrm{~h}$ and analyzed. The particular antioxidants and inhibitors were administered as follows: MnTMPyP (5 $\mu \mathrm{M}$ added to cells $24 \mathrm{~h}$ prior to zinc exposure), Pifithrin- $\alpha$ (30 $\mu \mathrm{M}$ - added to cells $24 \mathrm{~h}$ prior to zinc treatment), SP600125 and SB 203580 (both at $10 \mu \mathrm{M}$ - supplemented to cells 30 min before exposure to zinc) and U1026 (20 $\mu \mathrm{M}$ - administered to cells $2 \mathrm{~h}$ before exposure to zinc).

\section{Measurement of free intracellular zinc concentrations}

Free intracellular zinc in Hep-2 cells treated with zinc as described above was monitored using microfluorometry of the zinc-specific dye Newport Green diacetate (6). Briefly, cells grown in black-bottom 96-well plates were incubated with Newport Green diacetate $(5 \mu \mathrm{mol}$ in PBS, dark, 30 min at $37^{\circ} \mathrm{C}$ ) and fluorescence intensity was determined by a multiplate reader TECAN SpectraFluor Plus (TECAN Austria GmbH, Grödig, Austria) at 485 and $535 \mathrm{~nm}$, respectively with stable integration time $1000 \mathrm{~ms}$ and gain 150. The results in relative light units (RLU) were obtained from raw data minus reagent blank and expressed as percentage of the fluorescence intensity of controls.

\section{Assays of ERK, p38 and JNK activities}

Treated and control cells were harvested and collected by centrifugation. Whole cell extracts were prepared and ERK, p38 and c-Jun N-terminal kinase (JNK) activities were measured using Elisa kits (Sigma-Aldrich, St. Luis, MO, USA and Calbiochem, San Diego, CA, USA) specific for total ERK and phospho-ERK (pTpY $\left.{ }^{185 / 187}\right)$, total and phospho-p38 (pTpY ${ }^{180 / 182}$ ), and total and phospho-JNK

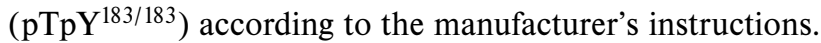
The assays were performed in 96-well plate format and samples were read against standard curves obtained from ERK and phospho-ERK, p38 and phospho-p38 and JNK and phospho-JNK standards. Results were normalized to micrograms of protein in the cell extract and expressed as the ratio of phosphor-to total kinase in the same sample. The results of zinc treatment were expressed as percentage of control values.

\section{Western blot analysis}

Zinc-treated and control cells were harvested at different time intervals with trypsin, washed with PBS and centrifuged $\left(1000 \mathrm{rpm}, 5 \mathrm{~min}, 4{ }^{\circ} \mathrm{C}\right)$. The resulting pelet was resuspended in $5 \mathrm{ml}$ of ice-cold lysis buffer $(137 \mathrm{mM} \mathrm{NaCl}$, $10 \%$ glycerol, $1 \%$ n-octyl- $\beta$-D-glucopyranoside, $50 \mathrm{mM} \mathrm{NaF}$, $20 \mathrm{mM}$ Tris, $1 \mathrm{mM}$ sodium orthovanadate, Complete TMMini).

The whole cell lysates were boiled for $5 \mathrm{~min} / 95{ }^{\circ} \mathrm{C}$ in SDS sample buffer (Tris-HCl pH 6.81, 2-mercaptoethanol, $10 \%$ glycerol, SDS, $0.1 \%$ bromphenol blue) and thereafter they were loaded onto a $12 \% \mathrm{SDS} /$ polyacrylamide gel. Each lysate contained an equal amount of protein $(30 \mu \mathrm{g})$ as determined by bicinchoninic acid assay (BCA assay) (Sigma-Aldrich, Prague, Czech Republic). After electrophoresis, proteins were transferred to a PVDF membrane $(100 \mathrm{~V}, 60 \mathrm{~min})$ and incubated at $25^{\circ} \mathrm{C}$ for $1.5 \mathrm{~h}$ with a solution containing $5 \%$ nonfat dry milk, $10 \mathrm{mM}$ Tris- $\mathrm{HCl}(\mathrm{pH}$ 8.0), $150 \mathrm{mM}$ sodium chloride, and $0.1 \%$ Tween 20 (TBST). Membranes were incubated with primary antibodies (monoclonal mouse anti-p53, 1:500, monoclonal mouse anti-phosphorylated p53, 1:750 and monoclonal mouse anti- $\beta$-actin, $1: 100)$ at $4{ }^{\circ} \mathrm{C}$ overnight followed by $6 \mathrm{~min}$ of washing five times in TBST. Next, the blots were incubated with secondary peroxidase-conjugated antibodies (1:1000, $1 \mathrm{~h}, 25^{\circ} \mathrm{C}$ ), washed with TBST and the signal was developed with a chemiluminescence (ECL) detection kit (Boehringer Mannheim-Roche, Basel, Switzerland).

\section{Determination of cell death}

The presence of cell death in zinc-treated cells was evaluated by the nuclear architecture and the presence of caspase-3 as described before (14). Briefly, treated and control cells grown on coverslips were fixed with $2 \%$ parafor- 
maldehyde, blocked in skimmed milk for 30 min and subjected to immunofluorescent detection of activated caspase-3 using a polyclonal rabbit anti caspase-3 antibody (1:50, $\left.2 \mathrm{~h}, 25^{\circ} \mathrm{C}\right)$. The nuclear architecture was observed simultaneously after staining samples with DAPI $(1 \mathrm{mg} / \mathrm{ml}, 5$ min, $25^{\circ} \mathrm{C}$ ). Quantitative data from samples were obtained from cell cytometric analysis using Lucia Nis elements software analyzing at least 2,000 cells per coverslip.

\section{Statistics}

Statistical analysis was carried out with a statistical program GraphPad Prism (GraphPad Software, Inc. San Diego, USA). We used a one-way Anova test with Dunnett's post test for multiple comparisons. Results were compared with control samples and means were considered significant if $\mathrm{P}<0.05$.

\section{Results}

\section{Changes in intracellular free zinc concentrations in Hep-2 cells}

Hep- 2 cells were first left for $24 \mathrm{~h}$ in zinc-free cultivation medium. This time interval was sufficient for reducing free intracellular zinc stores (Fig. 1) while having no effect on cell viability. Upon the following exposure of thus treated cells to $150 \mu \mathrm{M}$ zinc, intracellular free zinc abundance was quickly restored (within several hours of treatment) and in the interval of 6 to $16 \mathrm{~h}$ of exposure these free zinc levels were significantly elevated (Fig. 1).

\section{Zinc induces the expression and phosphorylation of $p 53$}

Since zinc has been shown to produce oxidative stress and possibly damage DNA, we examined the level of p53 in treated Hep- 2 cells. The p53 protein level was already augmented at $4 \mathrm{~h}$ and reached significant elevation at $8 \mathrm{~h}$ of treatment (Fig. 2 upper panel). Phosphorylation of the Serine- 15 residue is known to be a very early step in the activation of $\mathrm{p} 53$. We have thus assessed this step by means of a specific antibody recognizing the phosphorylated Serine- 15 residue of $p 53$. The phosphorylation of Serine- 15 paralleled the increased expression of p53 in treated Hep-2 cells and reached its maximum at around $8 \mathrm{~h}$ (Fig. 2 lower panel).

\section{Zinc activates $p 38, J N K$ and ERK}

There is a recognized functional linkage between phosphorylation of p53 and activation of various kinases. In order to verify the involvement of the three members of the MAPK family, p38, JNK and ERK, we measured their activities in zinc treated Hep-2 cells using specific Elisa functional assays. As shown in Fig. $3 \mathrm{~A}-\mathrm{C}$, we found that zinc caused a very early activation of all three examined kinases but the kinetics of their activities differed significantly. While p38 showed the most sustained and massive activity which peaked at $16 \mathrm{~h}$ of treatment, JNK and ERK activities were relatively short-lived, with their maxima being reached at $6 \mathrm{~h}$ and $8 \mathrm{~h}$ of exposure, respectively.

To further test the roles of individual MAPKs in p53 phosphorylation, we employed their selective inhibitors. Fig. 4 shows that neither of these inhibitors was capable of abrogating zinc-mediated p53 phosphorylation at Serine- 15 in Hep-2 cells; however, p38-specific inhibitor SB 203580 proved to have a more significant inhibitory effect than other inhibitors, in particular ERK inhibitor U0126.

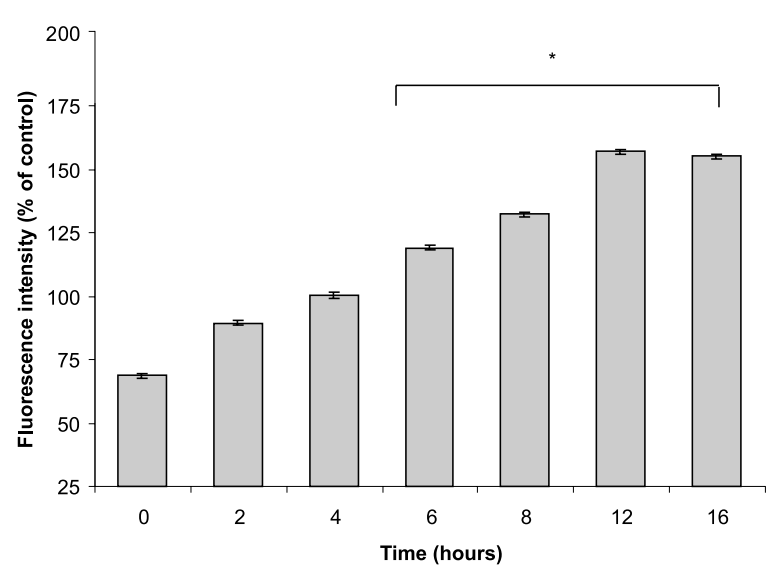

Fig. 1: Time course of changes in intracellular free zinc concentrations in Hep-2 cells treated with $150 \mu \mathrm{M}$ zinc during $24 \mathrm{~h}$. Cells were first cultivated in a zinc-free medium for $24 \mathrm{~h}$ and then exposed to cultivation medium supplemented with zinc. Intracellular free zinc levels were determined spectrofluorimetrically. Results were expressed as a percentage of the untreated control and considered significant if $<0.05$ with one way-Anova test and Dunnett's post test for multiple comparisons. Values represent the mean \pm SD of three independent experiments.

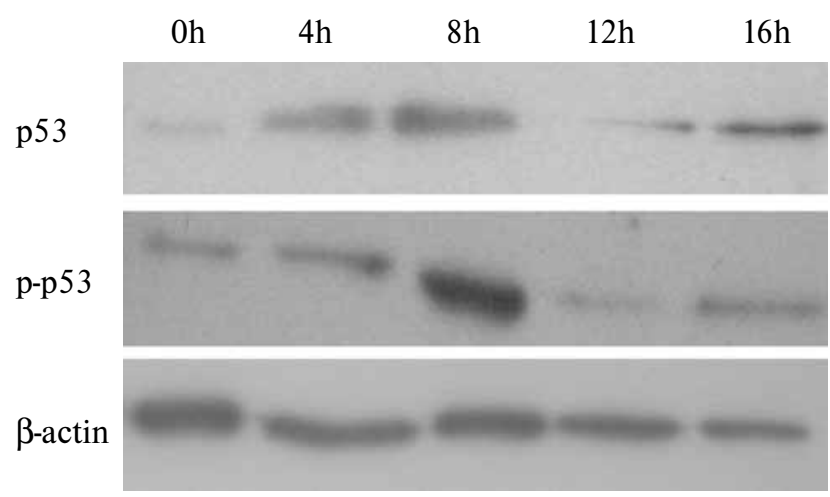

Fig. 2: Accumulation and phosphorylation of p53 in Hep2 cells treated with $150 \mu \mathrm{M}$ zinc during $16 \mathrm{~h}$. Treated cells and controls were harvested and the p53 detection was performed by means of immunodetection as described in the Material and Methods section. The experiment was repeated three times. 

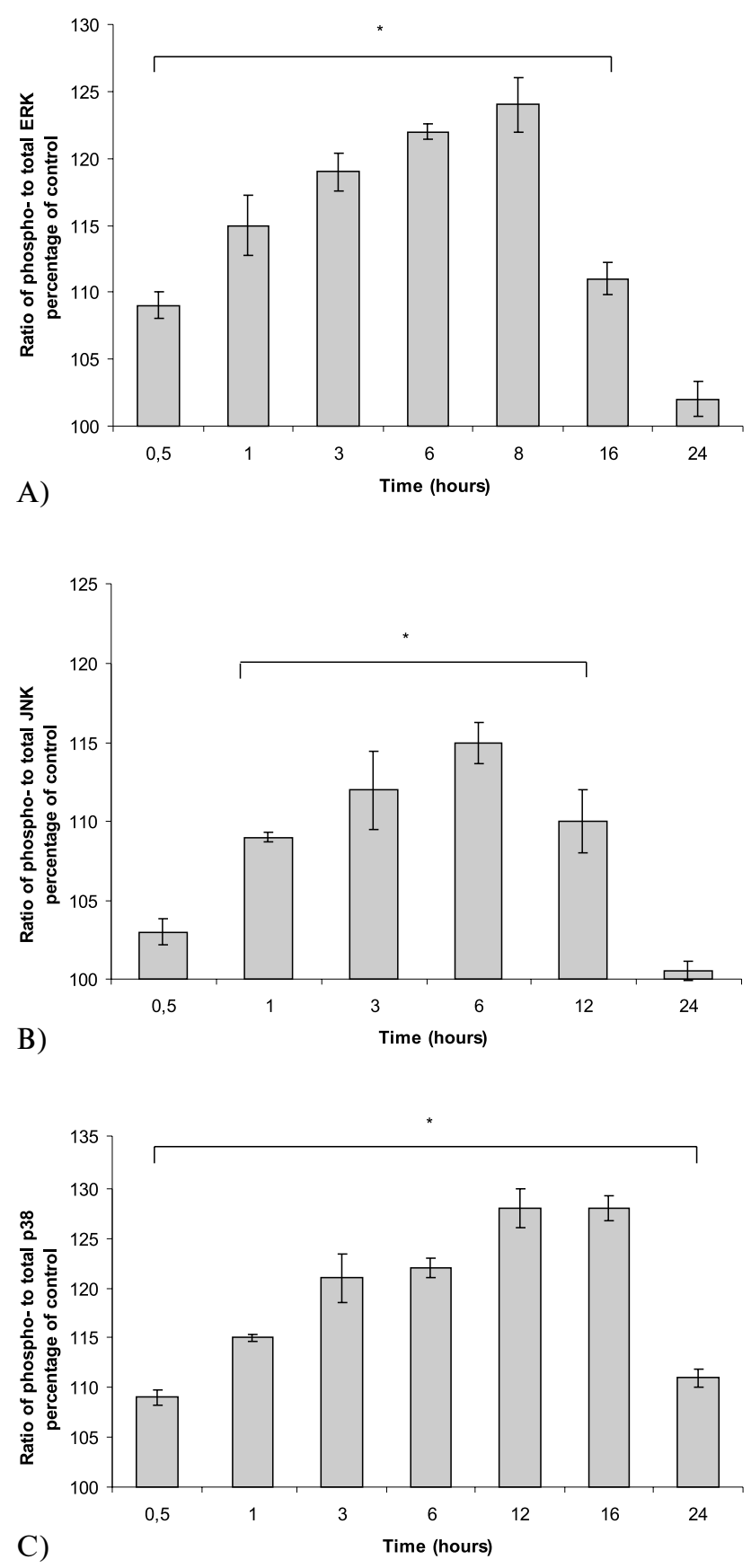

Fig. 3: Activation of MAPK in zinc treated Hep-2 cells. Treated and control cells (both deprived of zinc $24 \mathrm{~h}$ prior to experiments) were harvested and the activities of $\mathrm{p} 38$, JNK and ERK kinases were determined spetrofotometrically as described in the Material and Methods section. (A) ERK (B) JNK (C) p38. Results were expressed as a percentage of the control of the ratio of phospho-to total MAPK. Values represent the mean \pm SD of three independent experiments. ${ }^{*} \mathrm{P}<0.05$ significantly different from the control with one way-Anova test and Dunnett's post test for multiple comparisons.

\section{Subacute exposure of cells to zinc induces apoptosis by varying mechanisms}

Upon differing exposure, zinc may cause cell injury and cell death by several mechanisms, including well established propoptotic pathways and substrates. In our present experiments, we wanted to verify the role of MAPK-p53-dependent pathways in Hep-2 cells exposed to subacutely increased intracellular free zinc levels. Apoptosis was determined by means of caspase- 3 activation and chromatin fragmentation, as described previously. In addition, we assessed the effect of various MAPK inhibitors as well as the specific p53 inhibitor on the execution of cell death. Control cultures with normal zinc content show a very low level of spontaneous apoptosis (up to $3 \%$ at $24 \mathrm{~h}$ of cultivation - Fig. 5B). Conversely, subacutely increased free zinc abundance in Hep-2 cells leads to a rapid activation of caspase-3, with subsequent chromatin fragmentation peaking at $16 \mathrm{~h}$ of treatment (Fig. 5A). All the employed pharmacologic inhibitors expcept for Pifithrin- $\alpha$ had only a partial effect on the execution of zinc-stimulated apoptosis, and their efficiency varied between 20 to $35 \%$. Pifithrin- $\alpha$ proved to be a decisive and significant inhibitor, abrogating almost completely caspase- 3 activation and nuclear condensation (Fig. 5C).

\section{Discussion}

Eukaryotic cells maintain intracellular zinc homeostasis by means of intricate mechanisms including various zinc

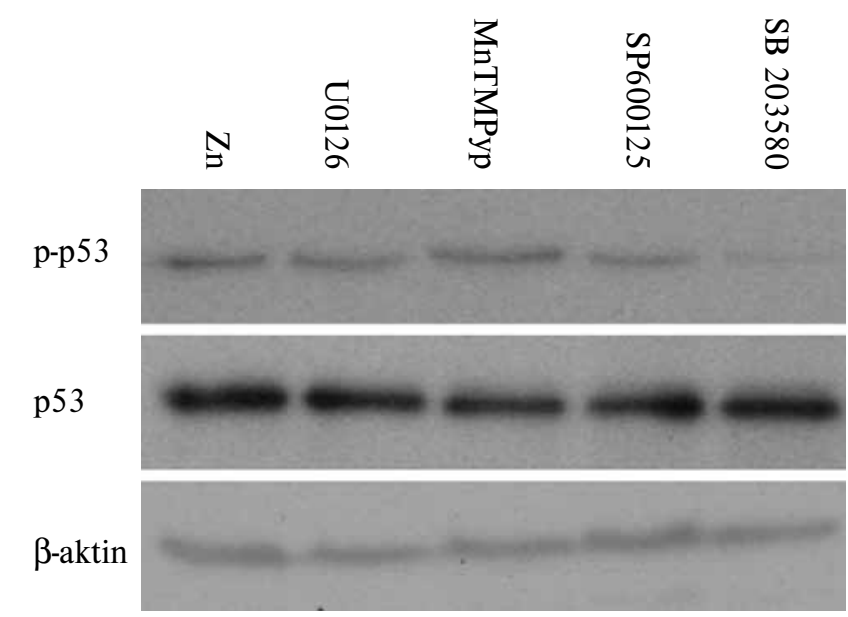

Fig. 4: The effect of MAPK selective inhibition and oxidative stress inhibition on the p53 phosphorylation in zinctreated Hep-2 cells. Cells were pretreated with specific MAPK inhibitors (p38-specific inhibitor SB 203580, JNKspecific inhibitor SP600125 and ERK (MEK)-specific inhibitor U0126) and sodium catalase mimetic MnTMPyP and after exposure to zinc for $8 \mathrm{~h}$ the $\mathrm{p}-53$ phosphorylation was determined with help of Western blotting as described in the Material and Methods. The experiment was repeated three times. 
transporters as well as zinc-binding and sequestering mechanisms (3). The purpose of these mechanisms is to keep free zinc abundance in the cytosol at optimal levels. In case of elevation of free zinc stores cells sustain damage which often results in cell death, as has been shown in various experimental models $(1,4)$. To study effects of elevated free intracellular zinc levels under normal situation, however, it is necessary to expose cells to sometimes excessive external zinc concentrations or to use so called zinc-specific ionophores that mediate direct entry of zinc into the cytosol (10). Both approaches have their disadvantages, and therefore we decided to employ more the "physiological" approach by manipulating the ability to import and retain more free zinc via changed external cultivation conditions, which allow for an increased internalization and availability of zinc. We found that exposure of thus manipulated Hep-2 cells to zinc at concentration of $150 \mu \mathrm{M}$ for $24 \mathrm{~h}$ significantly increases intracellular free zinc abundance within hours. The fact that free zinc levels did not dwindle at later treatment periods indicate that the speed and extent of incoming zinc pools was clearly exhaustive for any homeostatic mechanisms the cells might otherwise have employed, thereby establishing a situation which might better reflect real conditions within an organism.
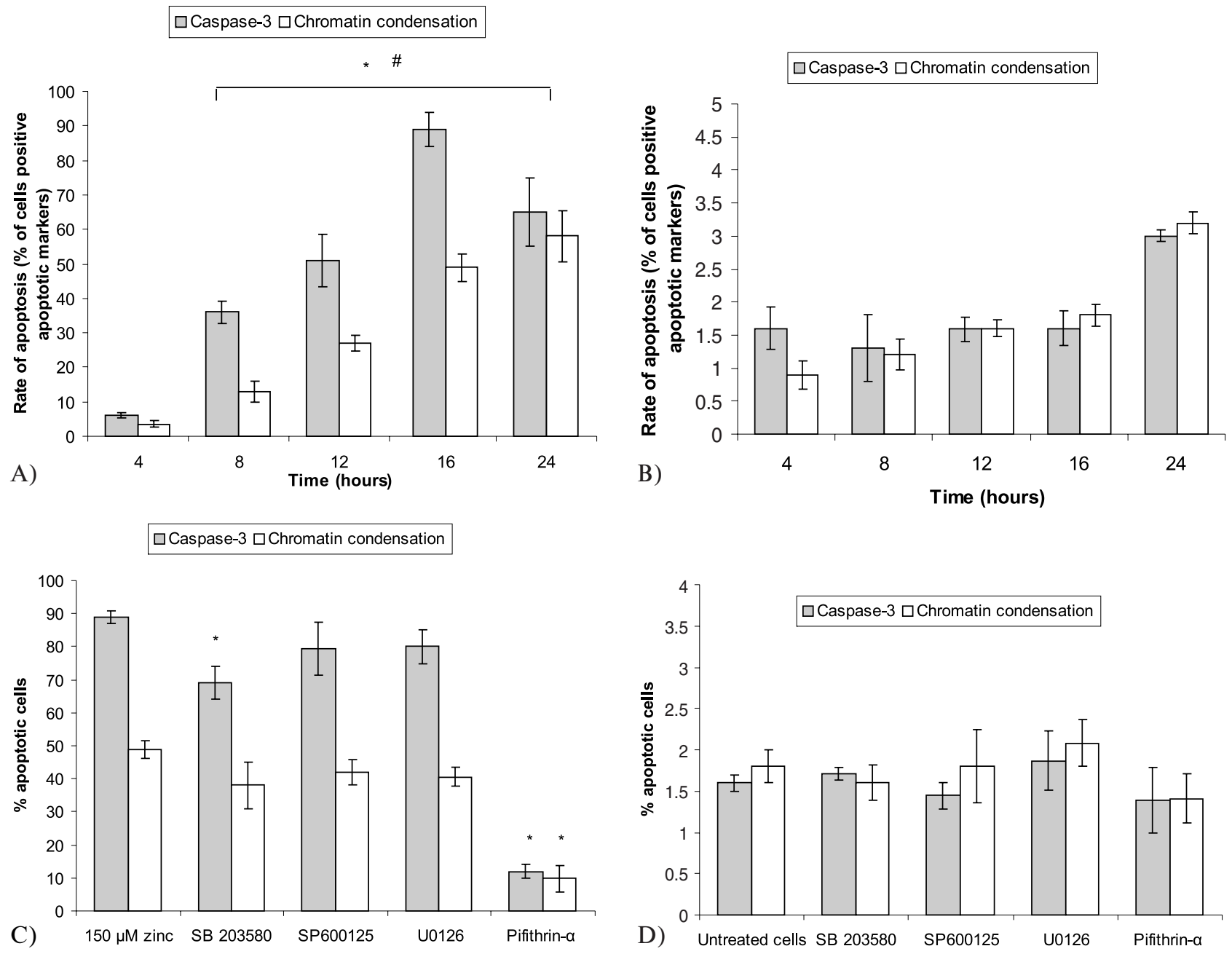

Fig. 5: Rate of apoptosis in Hep-2 cells exposed to $150 \mu \mathrm{M}$ zinc during $24 \mathrm{~h}$. (A) Time course of apoptosis as measured by immunofluorescent detection of caspase-3 and fluorescent detection of nuclear condensation as described earlier. (B) Time course of activation of caspase- 3 and nuclear condensation in untreated Hep-2 cells (C) Effect of specific MAPK inhibitors (p38-specific inhibitor SB 203580, JNK-specific inhibitor SP600125 and ERK (MEK)-specific inhibitor U0126) and p53 inhibitor Pifithrin- $\alpha$ on apoptosis at $16 \mathrm{~h}$ of treatment (D) Effect of specific MAPK inhibitors (p38-specific inhibitor SB 203580, JNK-specific inhibitor SP600125 and ERK (MEK)-specific inhibitor U0126) and p53 inhibitor Pifithrin- $\alpha$ on apoptosis at $16 \mathrm{~h}$ in control Hep- 2 cultures. Values represent the mean \pm SD of three independent experiments. *\#P<0.05 significantly different from control with one way-Anova test and Dunnett's post test for multiple comparisons. 
From our previous experiments we know that in Hep-2 cells zinc induces apoptosis, which is characterized by the involvement of oxidative stress, $\mathrm{p} 53$ and mitochondria, and which is executed both caspase-dependently and -independently (15). Hence we wanted to know more details about the role of p53 in this process and, namely, to explore a mechanism whereby this protein could be activated. Given the fact that zinc has been reported to generate oxidative stress and/or DNA damage, it was reasonable to suppose that p53 activation would play a significant role in integrating possible DNA damage signals with proapoptotic machinery. Genotoxic stresses generally lead to phosphorylation of p53, especially in serine- 15 , which in turn promotes accumulation and functional activation of p53 (8). The presented results confirm this observation, as they show that in Hep2 cells concomitant with p53 phosphorylation there was an increased accumulation of $\mathrm{p} 53$ protein. Phosphorylation of p53 is generally mediated by a variety of factors, including protein kinases such as DNA-dependent protein kinase, ATM, ATR, Jun kinases, extracellular signal-related protein kinases (ERKs), and p38 MAPK (17). We have examined the activities of three members of these kinases - p38, JNK and ERK in zinc exposed Hep-2 cells. Of all three examined MAPK, the activation of $\mathrm{p} 38$ was found to be the most significant and long-lasting. On the other hand, JNK and ERK showed the least amount of activation, and the shortest lived too. Our observation seems to be in contrast with other reports which document the involvement of special isoforms of ERK in zinc mediated toxicity and cell death (7). Nevertheless, since we have not focused on all ERK isoforms, their role in proapoptotic signaling cannot be ruled out and deserves further examination in the future. Pretreatment with specific MAPK inhibitors had a relatively low effect on p53 accumulation and phosphorylation; however, the most potent was the $\mathrm{p} 38$ inhibitor, suggesting a role for $\mathrm{p} 38$ MAPK in zinc-induced p53 phosphorylation. There is evidence suggesting that p38 MAPK directly phosphorylates p53 in serine-33 (18) and serine-46 (11). Concerning the role of p38 in phosphorylation in serine-15, available reports supply unclear data and it remains to be seen whether, in this case, p38 is directly involved or whether its effect represents just a redundant mechanism (8). Our recent investigations may provide some answers, as we found that the use of wortmannin, a selective inhibitor of DNA-PK and ATM, significantly, although not totally, prevented p53 phosphorylation in serine-15 (unpublished observations).

In our recent work we discovered that treatment of Hep-2 cells with external zinc during $96 \mathrm{~h}$ induces p53-dependent as well as -independent apoptosis (15). To verify the involvement of p53 in cell injury and apoptosis of Hep2 cells subacutely exposed to external zinc during $24 \mathrm{~h}$, we employed Pifithrin- $\alpha$, a specific p53 inhibitor, and determined the rate of apoptosis. We found that pretreatment of zinc-exposed cells with this inhibitor significantly reduced the numbers of apoptotic cells. Furthermore, apoptosis was abrogated even more extensively in the presence of a cata- lase-mimetic antioxidant. These observations fully implicate p53 in propapoptotic signaling in Hep-2 cells treated with subacute zinc, and suggest that oxidative stress (12) plays a significant role in the activation of cell death and possibly in the activation of p53 too. Since we as well as other authors have found that upon its entry inside the cell zinc generates oxidative stress, it is reasonable to hypothesize that oxidative stress damages DNA and directly or indirectly activates the p53 pathway by acting on upstream signaling molecules such as apoptosis signal-regulated protein kinase (ASK-1) (16). Stimulation of these molecules might lead to activation of MAPKs in the presence of a suppressed thioredoxin system. Thus, zinc-induced oxidative stress may serve here as an ultimate feedback amplification mechanism, acting on several levels of one cascade leading to the final cell demise.

\section{Conclusion}

Subacute treatment of Hep-2 cells with extracellular zinc induces an increase in intracellular free zinc levels leading to p53 accumulation and its phosphorylation in serine15. The same treatment induces differential activation of MAP kinases p38, JNK and ERK. The specific inhibition of these kinases has a varying effect on the observed p53 phosphorylation, suggesting a major role for $\mathrm{p} 38$ in this process. Zinc induced caspase- 3 activation can be significantly prevented by specific p53 inhibition as well as by abrogation of oxidative stress. These data show that oxidative stress is one of the key players in p53-dependent cell demise mediated by zinc in tumor Hep-2 cells.

\section{Acknowledgement}

This work was supported by the Ministry of Education Research Project MSM 0021620820.

\section{References}

1. Feng P, Li TL, Guan ZX, Franklin RB, Costello, LC. Direct effect of zinc on mitochondrial apoptogenesis in prostate cells. The Prostate 2002;52:311-8.

2. Fraker PJ, Telford WG. A reappraisal of the role of zinc in life and death decisions of cells. Proceedings of the Society For Experimental Biology and Medicine 1997;215:229-36

3. Haase H, Beyersmann, D. Intracellular zinc distribution and transport in C6 rat glioma cells. Biochemical and Biophysical Research Communications 2002; 296:923-8.

4. Choi DW, Koh JY. Zinc and brain injury. Annual Review of Neuroscience 1998; 21:347-75.

5. Kindermann B, Doring F, Fuchs D, Pfaffl MW, Daniel H. Effects of increased cellular zinc levels on gene and protein expression in HT-29 cells. Biometals 2005; $18: 243-53$

6. Kindermann B, Doring F, Pfaffl M, Daniel H. Identification of genes responsive to intracellular zinc depletion in the human colon adenocarcinoma cell line HT29. J Nutr 2004;134:57-62.

7. Klein $\mathrm{C}$, Creach K, Irintcheva V et al. Zinc induces ERK-dependent cell death through a specific Ras isoform. Apoptosis 2006;11:1933-44.

8. Kwon YW, Ueda S, Ueno M, Yodoi J, Masutani H. Mechanism of p53-dependent apoptosis induced by 3-methylcholanthrene: involvement of $\mathrm{p} 53$ phosphorylation and p38 MAPK. The Journal of biological chemistry 2002;277:1837-44.

9. Liuzzi JP, Cousins RJ. Mammalian zinc transporters. Annual Review of Nutrition 2004;24:151-72.

10. Mann JJ, Fraker PJ. Zinc pyrithione induces apoptosis and increases expression of Bim. Apoptosis 2005;10:369-79. 
11. Oda K, Arakawa H, Tanaka T et al. p53AIP1, a potential mediator of $\mathrm{p} 53$-dependent apoptosis, and its regulation by Ser-46-phosphorylated p53. Cell 2000;102:849-62

12. Provinciali M, Donnini A, Argentati K, Di Stasio G, Bartozzi B, Bernardini G Reactive oxygen species modulate $\mathrm{Zn}(2+)$-induced apoptosis in cancer cells. Free Radical Biology \& Medicine 2002;32:431-45.

13. Roux PP, Blenis J. ERK and p38 MAPK-activated protein kinases: a family of protein kinases with diverse biological functions. Microbiol Mol Biol Rev 2004 68:320-44.

14. Rudolf E, Cervinka M. Cytoskeletal changes in non-apoptotic cell death. Acta Medica (Hradec Kralove) 2006;49:123-8
15. Rudolf E, Rudolf K, Cervinka M. Zinc induced apoptosis in HEP-2 cancer cells: the role of oxidative stress and mitochondria. Biofactors 2005;23:107-20.

16. Saitoh M, Nishitoh H, Fujii M et al. Mammalian thioredoxin is a direct inhibitor of apoptosis signal-regulating kinase (ASK) 1. The EMBO journal 1998;17: 2596-606.

17. Shieh SY, Ikeda M, Taya Y, Prives C. DNA damage-induced phosphorylation of p53 alleviates inhibition by MDM2. Cell 1997;91:325-34.

18. Takekawa M, Adachi M, Nakahata A et al. p53-inducible Wip1 phosphatase mediates a negative feedback regulation of p38 MAPK-p53 signaling in response to UV radiation. The EMBO journal 2000;19:6517-26.

Submitted January 2008.

Accepted March 2008

\section{Corresponding author:}

Doc. PharmDr. Emil Rudolf, Ph.D., Charles University in Prague, Faculty of Medicine in Hradec Králové, Department of Medical Biology and Genetics, Šimkova 870, 50038 Hradec Králové, Czech Republic, e-mail: rudolf@lfhk.cuni.cz 